\title{
Removal of Acid Orange 7 dye from aqueous solutions by adsorption onto Kenya tea pulps; granulated shape
}

\author{
Behnaz Naraghi ${ }^{1}$, Fahimeh Zabihi ${ }^{1}$, Mohammad Reza Narooie ${ }^{2}$, Mahdi Saeidi ${ }^{3}$, Hamed Biglari ${ }^{4}$
}

${ }^{1}$ MSc. of Environmental Health, Senior Lecturer, Department of Environmental Health Engineering, School of Public Health, Birjand University of Medical Sciences, Birjand, Iran

${ }^{2}$ MSc. of Environmental Health, Senior Lecturer, Department of Environmental Health Engineering, School of Public Health, Iranshahr University of Medical Sciences, Iranshahr, Iran

${ }^{3}$ M.Sc. of Environmental Health, Senior Lecturer, Department of Environmental Health Engineering, School of Public Health, Torbat Heydariyeh University of Medical Sciences, Torbat Heydariyeh, Iran

${ }^{4}$ MSc. of Environmental Health, Senior Lecturer, Department of Environmental Health Engineering, School of Public Health, Gonabad University of Medical Sciences, Gonabad, Iran

\section{Type of article: Original}

\begin{abstract}
Background and Aim: Water resources pollution control is one of the main challenges of our time for researchers. Colored wastewater discharges caused by textile industry activities has added to the concern. In this study, removal of Acid Orange 7 dye (AO7) using Kenya Tea residue absorbent (granular) has been studied.

Methods: This cross-sectional study was conducted in 2016. In this work, initially, tea residue was prepared in three forms of raw, treated with concentrated phosphoric acid, and carbonated, at temperatures of 350,450 and $500{ }^{\circ} \mathrm{C}$ in the chemistry laboratory of Gonabad University of Medical Sciences. Then, efficiency of the above absorbents in the removal of Acid Orange 7 dye in initial concentrations of dye as $50-500 \mathrm{mg} / \mathrm{l}$ from water samples in terms of $\mathrm{pH} \mathrm{2-10} \mathrm{and} \mathrm{1-10} \mathrm{g/l} \mathrm{of} \mathrm{adsorbent} \mathrm{dose} \mathrm{within} 20$ to 300 minutes was investigated. In addition, their subordination from Langmuir and Freundlich absorption isotherms was also determined. Concentration changes in Acid Orange 7 dye at a wavelength of $483 \mathrm{~nm}$ was determined by spectrophotometry and results were reported using descriptive statistics.

Results: Results showed that efficiency of Acid Orange 7 dye removal is higher in acidic $\mathrm{pH}$ and higher adsorbent dosage. The highest efficiency of Acid Orange 7 dye removal was $98.41 \%$ by raw tea residue absorbent at $\mathrm{pH} 2$, reaction time was 120 minutes and initial concentration of dye was $50 \mathrm{mg} / \mathrm{l}$, which was obtained at adsorbent dosage of $10 \mathrm{~g} / \mathrm{l}$. It was determined that the mechanism of absorption acceptably follows Freundlich absorption isotherm $\left(\mathrm{R}^{2}=0.97\right)$.

Conclusion: Due to the availability and very low price, optimal performance of Kenya tea raw residue (granular) in Acid Orange 7 dye removal, it can be used as an efficient surface absorber in an absorber from colored wastewater.
\end{abstract}

Keywords: Acid Orange 7, Dye Removal, Aqueous Solutions, Adsorption, Kenya Tea Pulps, Granulated Shape

\section{Introduction}

Increased production of color products and their high applications in today's world has led to production of colored wastewater and a serious concern for environmental researchers $(1,2)$. Wastewaters are produced or consumed in various industries, including textile and dyeing industries, pharmaceuticals, food industries, cosmetics production, paper making, tannery and similar industries (3). There is more than one million tons of annual production of dye worldwide used in different industries, especially in the textile industry as the second largest water consuming

\section{Corresponding author:}

Hamed Biglari, Department of Environmental Health Engineering, School of Public Health, Social Development \& Health Promotion Research Center, Gonabad University of Medical Sciences, Gonabad, Iran.

Tel: +98.5157225027 Fax: +98.5157223814, Email: Biglari.h@gmu.ac.ir

Received: June 24, 2016, Accepted: December 25, 2016, Published: May 2017

iThenticate screening: October 16, 2016, English editing: April 10, 2017, Quality control: May 02, 2017

(C) 2017 The Authors. This is an open access article under the terms of the Creative Commons Attribution-NonCommercialNoDerivs License, which permits use and distribution in any medium, provided the original work is properly cited, the use is non-commercial and no modifications or adaptations are made. 
industry in the world (4). Colored wastewater discharged to water resources causes undesirable appearance, loss of ability to use it in urban affairs, agriculture, industry and creates an aesthetically undesirable environment $(5,6)$. Generally, the dyes, especially azo dyes have a complex aromatic, toxic, mutagenic and carcinogenic structure and have high stability against sunlight (7-9). Discharging wastewater containing azo dyes not only affects the aesthetic aspect of receptor waters, but also causes the blocking of sunlight passing through the body of water and reduces photosynthesis process and dissolved oxygen concentration. About $12 \%$ of the dyes used in the textile industry enter wastewater, and about $20 \%$ of them are discharged to the environment without treatment $(10,11)$. Acid Orange 7 is among the acidic azo dyes which causes damage to the eyes and skin, and has chronic toxicity and carcinogenicity (12). Today, under intense pressure from public opinion and regulations of conventions, industries are required to treat their wastewater favorably before discharge into the natural environment (13-15). Thus, finding effective treatment methods is necessary and inevitable. Until now, various processes including electrochemical coagulation processes, oxidation, chemical precipitation, anaerobic treatment, flotation, and ion exchange for removal of dyes from aqueous solutions have been studied (16-19). Surface adsorption process is one of the environmentally-friendly processes with simple and economic mechanisms which, in recent decades, has become very famous in wastewater treatment $(20,21)$. In this method, using activated carbon or raw and inactivated biological materials such as bentonite, ash, and agricultural waste is very common for effective removal of soluble contaminant particles especially organic contaminants such as paint, from the aquatic environment (22). Some of the advantages of the surface absorption method are its low initial cost, simple design and operation, need for much lower energy source, lack of influence of toxic materials in great removal of contaminants with organic nature compared to other conventional treatment methods and non-selective functioning $(21,23)$. But restrictions in surface adsorption process such as increased suspended solids in water caused by powder form applications and their difficult separation, especially carbon forms from the water environment, have caused engineers to fix these separation problems and make changes in the form of absorbent application (24). In addition, in order to reduce preparation costs, the use of inexpensive materials such as remains of crops for production biodegradable biological absorbents has been highly regarded as a potential option (25). Meanwhile, using food residues has been considered in several studies due to reduction of biomass management cost reduction, prevention from unsanitary accumulation of biological mass, production of capital from food and agricultural waste. In addition, the carbon obtained from food and agricultural waste has low ash content, acceptable hardness and high surface area and adequate porous structure, thus their use for production of bio-adsorbents has been considered (26). One of the food wastes, which has high production volumes, particularly in Asian countries, is tea residue or waste produced by tea-producing industries, especially in cold tea producing industries. Need for proper discharge of tea residue for prevention of allopathic adverse effects on soil, low cost, its natural quality and its availability has caused the attention of researchers to produce absorbent from it (27). Using tea residue is not permissible in other affairs such as production of compost due to its toxicity and biological resistance (28). Up to now, efficiency of tea residue as active powder carbon on cations and onion dye removal from water environments, has been studied in some works $(29,30)$. Since cellulosic residues are suitable options for producing surface absorbents, given the basic problem of powder absorbent separation from water environments, efficiency of Kenya tea (CTC tea) residue as granule in surface absorption of Acid Orange 7 dye from water solutions is studied for the first time in this study.

\section{Material and Methods}

\subsection{Materials}

Most of the chemicals used in this study, including Acid Orange 7 dye (Orange II) C16H11N2NaO4S, sodium hydroxide and hydrochloric acid were obtained from the reputable Merck Company from Germany. HPLC distilled water was used in all tests. Adjusting the $\mathrm{pH}$ was done by Denver Ultra basic-UB10 made in America using $1 \mathrm{~N} \mathrm{HCl}$ and $\mathrm{NaOH}$. At the present time, official or orthodox and non-official or CTC (Crush, Tear, Curl) methods are used in many of the world's tea industries to make tea, especially black tea. In CTC method, the new machines called CTC machines include a pair of opposing rotating rollers. CTC tea resembles an ant's head in appearance thus it also known as ant head tea in Persian language. In this technique, tea seeds are very convoluted. Therefore, in addition to high porosity and specific surface area, it retains its structure and cannot be torn apart in an aqueous environment, even in boiling water. With regard to high production and consumption of tea (there is daily production of 2100 tons of cold tea and tea waste just in iced tea production factories in Fars province in Iran), the use of CTC tea residue bio-absorbent for AO7 dye absorption is investigated in this work. To this end, at first, Kenya tea residue was prepared from the Sophia Iced Tea Factory located in Chabahar city (Sistan and Baluchistan, Iran). Then tea residue seeds were screened with a 30-mesh size of $0.5 \mathrm{~mm}$. To prepare fine-grained tea (ant's head tea (Kenya Tea)) residue absorbent as raw, acid treatment with concentrated phosphoric acid in a ratio of 3 to 1 and carbonation at temperatures of $0,300,500,800{ }^{\circ} \mathrm{C}$ (the needed temperature was already obtained) was used. In order to remove 
possible contamination, initially they were boiled in water so that no color was created, and after acid cleaning and neutralization, they were dried for 24 hours at $120{ }^{\circ} \mathrm{C}$. In the next stage, the dried tea residues were heated for 60 minutes in an electric furnace of the Alfa horizontal type model as necessary and were carbonated and were kept in a desiccator until the needed time (31).

\subsection{Procedure}

The dye used in this study was Acid Orange 7 (Orange II) of acidic type and now is extensively used in textile and paper industries. Experiments were followed by preparation of different concentrations (50, 100, 150, 200, 500 $\mathrm{mg} / \mathrm{l}$ ) of AO7 dye in the range of $\mathrm{pH} 2$ to 10 and adsorbent dosage of 1 to $10 \mathrm{~g} / \mathrm{l}$ based on a shaker with revolution of $100 \mathrm{rpm}$ for 120 minutes. At each stage of sampling, they were filtered by 42 micron Whatman filter paper, and dye concentration changes were determined using UV-vis spectrophotometer at a wavelength of $483 \mathrm{~nm}$. Microsoft Excel 2013 was used for data analysis and the results were reported based on descriptive statistics. Also, in order to determine maximum absorption and the optimum conditions for Langmuir and Freundlich isotherm, adsorption on the adsorbent were calculated and presented (13). To determine the structural properties of fine-grained tea residue, Electron Microscope Scanning by Philips XL-30 SEM Company was used and the Bruner -Taller- Emmet (BET) isotherm and fifth edition of Belsorp Japan software was used for determining the specific surface area.

\section{Results}

\subsection{Properties of Activated Carbon}

Investigation of Electron Microscope Scanning images prepared from tea residue indicates that this absorbent has amorphous structure and appropriate porous levels for appropriate and adequate absorption. The level of available surface based on the calculations by Belsorp software was determined as $832 \mathrm{~m} 2 / \mathrm{g}$. Since the specific surface area of the adsorbent is low, functional groups may have a more prominent role in the dye ion absorption from the liquid surface.

\subsection{Effects of Carbon Modifications}

The highest absorption rate in the raw adsorbent, acid treatment and carbon 350,450 and $500{ }^{\circ} \mathrm{C}$ at different temperatures on the dye absorption by absorbent was related to the raw, acidic, carbonated type with temperature of $450{ }^{\circ} \mathrm{C}$, carbonated type with a temperature of $350{ }^{\circ} \mathrm{C}$ and carbonated with temperature of $500{ }^{\circ} \mathrm{C}$ equivalent with $80.27,68.50,45.60,34.47$ and $29.47 \%$ respectively. Thus, results showed that acidic and thermal treatments had impact on absorption level of dye by tea residue, and highest absorption efficiency was obtained in raw absorbent as $98.41 \%$.

\subsection{Effect of $\mathrm{pH}$}

Figure 1 indicates impact of $\mathrm{pH}$ changes on Orange dye absorption rate in $\mathrm{pH}$ range between 2-10. Figure 1 indicates that dye absorption is highly reduced by increasing $\mathrm{pH}$ from 2 to 3 , and then the reduction trend is mild. After reaching to neutral $\mathrm{pH}$, absorption level has low reductive trend with increasing $\mathrm{pH}$. Thus, the highest efficiency of removal was obtained at $\mathrm{pH} 2$ as $98.41 \%$.

\subsection{Effect of Absorbent Dosage}

Figure 2 indicates impact of absorbent dosage on absorption rate of Acid Orange 7 dye. Figure 2 indicates that dye removal efficiency is increased by increasing absorbent dosage from 1-10 g/l, and concentration of residual dye was reduced to $0.795 \mathrm{mg} / \mathrm{l}$. Highest efficiency of removal was $98.41 \%$ in optimal dosage of $10 \mathrm{~g} / \mathrm{l}$.

\subsection{Effect of Initial Dye Concentration}

Figure 3 indicates impact of dye initial concentration change on absorption rate. Figure 3 indicates that dye removal efficiency is reduced to $79.65 \%$ from about $99 \%$ with increasing initial dye concentration from $50-500 \mathrm{mg} / \mathrm{L}$.

\subsection{Effect of Contact Time}

Figure 4 indicates impact of contact time change on dye adsorption rate. Figure 4 indicates that dye removal efficiency is increased by increasing time. Acid Orange 7 dye absorption efficiency was obtained as $98.31 \%$ at contact time of 120 minutes, while changes in dye absorption efficiency was low with increasing contact time as 120-300 minutes, and it is almost fixed. Dye removal efficiency was obtained as 99.14 after 300 minutes. Thus, optimal contact time was specified as 120 minutes. 


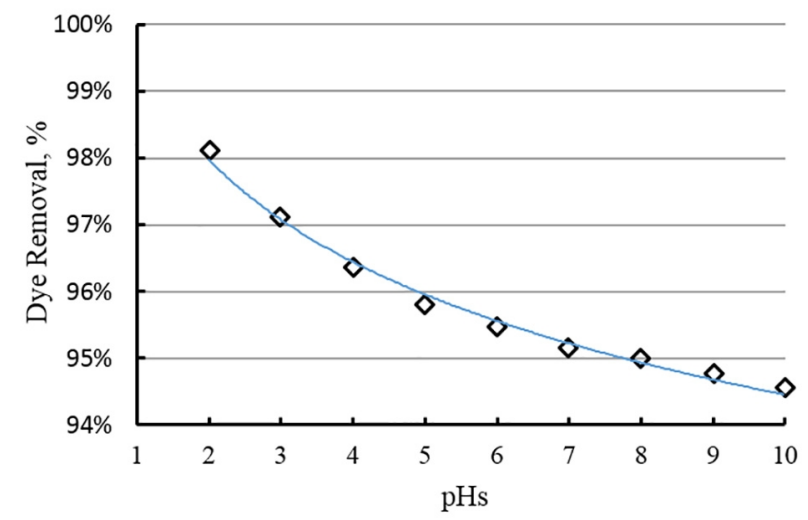

Figure 1. Effect of initial pH on Orange dye adsorption with tea pulp (Adsorbent dosage $10 \mathrm{~g} / \mathrm{l}$, dye con $50 \mathrm{mg} / \mathrm{l}$, Time $120 \mathrm{~min}$ )

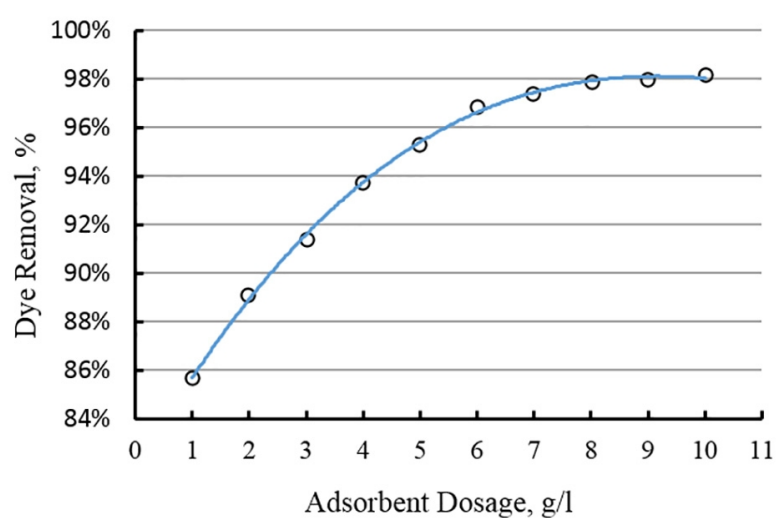

Figure 2. Effect of adsorbent dosage on AO7 dye with tea pulp (Adsorbent dosage $10 \mathrm{~g} / \mathrm{l}$, dye con $50 \mathrm{mg} / \mathrm{l}$, Time $120 \mathrm{~min}$, pH 2)

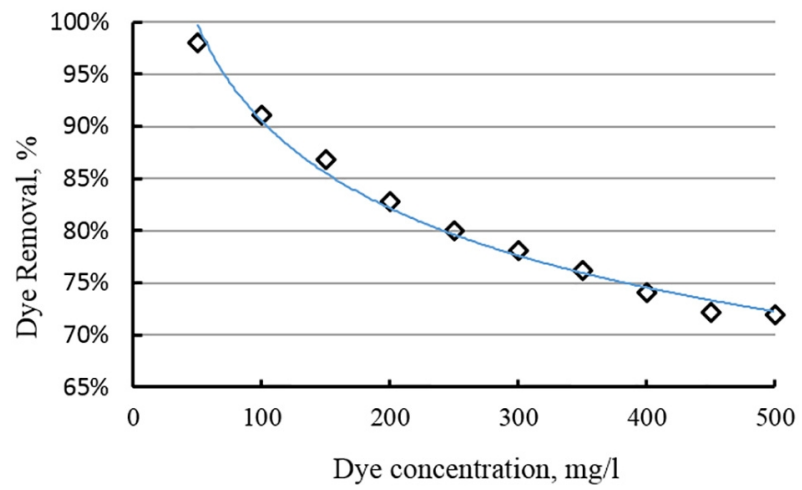

Figure 3. Effect of dye concentration on AO7 dye removal with tea pulp (Adsorbent dosage $10 \mathrm{~g} / 1$, Time $120 \mathrm{~min}, \mathrm{pH} 2$ )

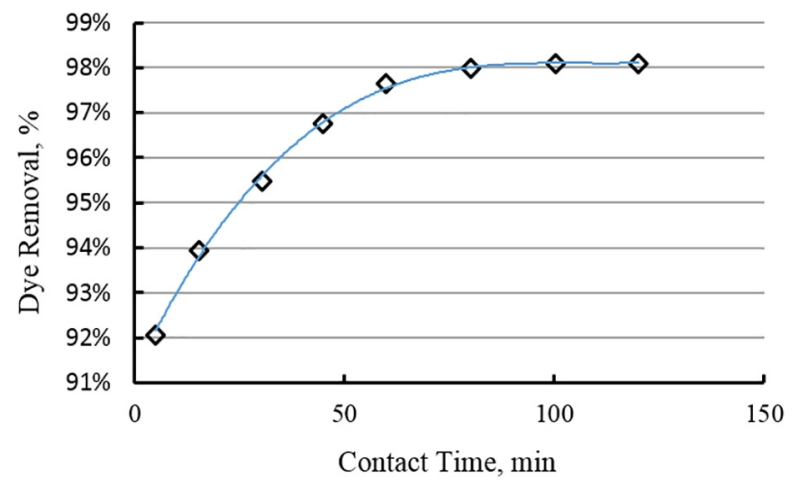

Figure 4. Effect of dye contact time on AO7 dye removal with tea pulp (Adsorbent dosage $10 \mathrm{~g} / \mathrm{l}$, dye con $50 \mathrm{mg} / \mathrm{l}, \mathrm{pH}$ 2) 


\subsection{Effect of Temperature}

Figure 5 indicates impact of variations in liquid ambient temperature on the absorption rate of dye. Figure 5 shows the dye removal efficiency increased with increasing temperature. So that the temperature increase from 30 to $50 \mathrm{C}$ and dye absorption efficiency also increases from 98.41 to $99.69 \%$.

\subsection{Adsorption Isotherm}

Figures 6 and 7 indicate amount of absorbed material on the surface in field temperature. Based on correlation coefficients $\left(\mathrm{R}^{2}\right)$ of isotherms of Langmuir and Freundlich adsorption models, as 0.85 and 0.97, respectively, it can be concluded that the adsorption rate of Acid Orange 7 dye on fine-grained tea residue follows Freundlich absorption isotherm considering higher correlation coefficient and $\mathrm{n}$ and $\mathrm{k}$ constant coefficients according to the equation curve is 2.46 and 4.31 , respectively.

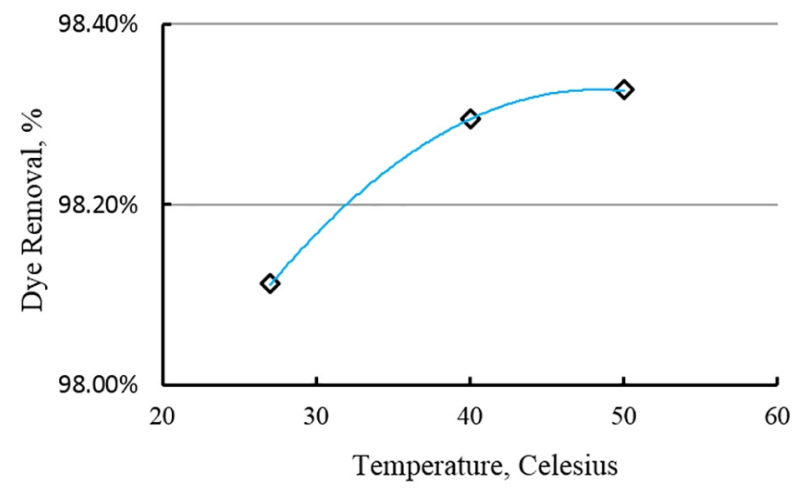

Figure 5. Effect of temperature on AO7 dye removal with tea pulp (Adsorbent dosage $10 \mathrm{~g} / \mathrm{l}$, dye con $50 \mathrm{mg} / \mathrm{l}$, contact time 120 min, $\mathrm{pH}$ 2)

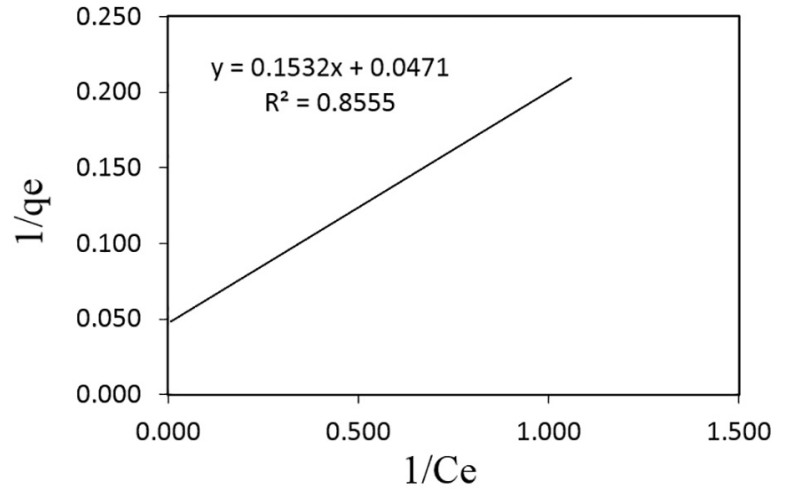

Figure 6. Isotherm of Langmuir of AO7 dye removal with tea pulp (Adsorbent dosage $10 \mathrm{~g} / 1$, contact time $120 \mathrm{~min}$, $\mathrm{pH}$ 2)

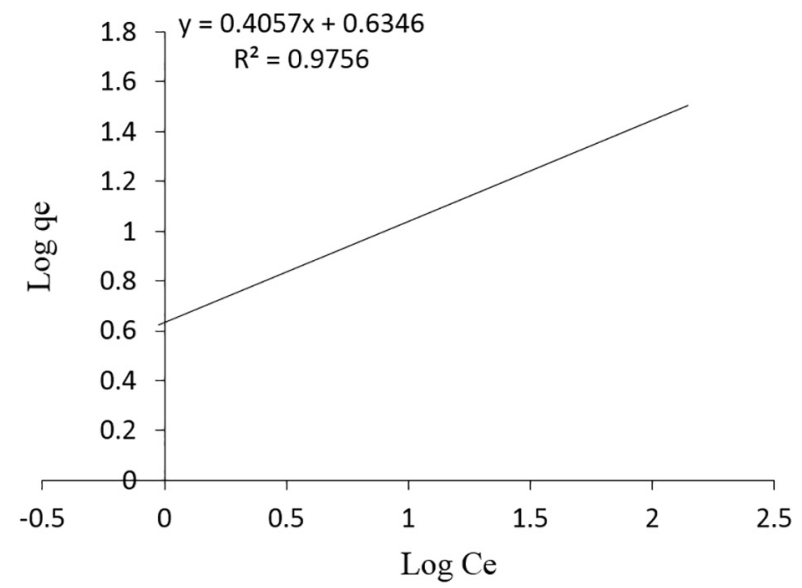

Figure 7. Isotherm of Freundlich of AO7 dye removal with tea pulp (Adsorbent dosage $10 \mathrm{~g} / 1$, contact time $120 \mathrm{~min}, \mathrm{pH}$ 2) 


\section{Discussion}

\subsection{Effect of Modifications}

Impact of change in raw absorbent, acidic treatment and carbonation in different temperatures on dye absorption level by fine-grained tea absorbent is shown in Figure 3. Carbonating bio-absorbents not only increases absorbent surface, but also can change acidic properties of the absorbent (32). Review of different studies has shown that the carbon prepared from tea residue in presence of activation agent causes increased dye absorption. In a study on adsorption of cationic and anionic dyes using activated carbon of tea residue reported that phosphoric acid as the activation agent in preparing activated carbon from tea residue have had good efficiency in removing contaminants (29). In another study, potassium acetate was used to produce activated carbon from tea for removal of methylene blue (27). But in this study, temperature without the activating factor (carbonation) was used. The results showed that this action does not affect the increasing dye removal efficiency. In the study on removal of cationic dye removal with the absorbent produced from rice bran carbon, it was reported that carbonating rice bran in temperatures of 600 and 800 causes reduction of absorption capacity compared to the raw samples, and absorption capacity is increased at temperature of 1000. They consider the reason for this as the physical properties of the absorbent (specific surface area and average diameter of the pores), and the absorbent surface area has a key role in dye removal (33). Also, acidic modification of absorbents causes improvement in their physical chemical and morphological properties leading to increased dye absorption (34). In the current study, acidic treatment had no significant impact on removal amount in the initial conditions of the experiment. Considering the fact that the highest removal efficiency was obtained with raw absorbent, and un-modified tea residue is more economical than carbonated and acidic samples, raw tea residue was used in this work for the next steps.

\subsection{Effect of $\mathrm{pH}$}

The $\mathrm{pH}$ of colored waters is effective in surface absorption and capacity absorption of dye. It results from change in the amount of ionization of factor groups available in absorption positions and thus, changing absorbent surface load and amount of ionization of the materials in the solution (35). Figure 4 indicates the impact of $\mathrm{pH}$ of coloring solutions in activated carbon absorption capacity prepared from fine-grained tea residue. Figure 4 shows that Acid Orange 7 dye is separated from aqueous environments in higher efficiency acidic pHs, so that absorption level was decreased to $93.6 \%$ from $98.41 \%$ by increasing $\mathrm{pH}$ from 2 to 10 . In the study on Acid Orange 7 dye removal from aqueous environments using bio-absorption technology, it has been reported that the highest dye removal was obtained in acidic $\mathrm{pH}$. The reason has been assigned to the presence of $\mathrm{H} 3 \mathrm{O}+$ ion, and in some cases, due to bonding $\mathrm{H}+$ ion with giving proton with the dye cations. Such bonding causes the removal of dye cations in greater amount and more efficiently (36). In the study on thermodynamic and equilibrium equations for removal of black 5 using acid modified banana peel, it is reported that removal efficiency decreased with increasing pH so the pH 2 and 7 respectively give 69.18 and $30.43 \%$ efficiency. It happens because of the close relationship between the binding sites of the adsorbent and hydrogen ions in the acid conditions which act as the ligand bond between the adsorbent surface and color molecules (37). In addition, sulfonate functional group in Acid Orange dye is ionized in water which causes that water molecules to become ionized. On the other hand, the $\mathrm{pH}$ rise increases negative charge in the absorbent and repulsive forces prevent acid orange absorption by the absorbent. The highest efficiency is obtained in acidic $\mathrm{pH}$ in this study, and it is consistent with the results of the above studies. Thus, in this study, the optimal $\mathrm{pH} 2$ is introduced as the optimal $\mathrm{pH}$.

\subsection{Effect of Absorbent Dosage}

Absorbent dosage is one of the main parameters in absorption process, which is due to determining role of absorbent capacity for absorbing contaminants at its surface (38). Figure 5 indicates the impact of absorbent concentration in the removal of dye in a fixed concentration of $50 \mathrm{mg} / \mathrm{l}$. It shows that efficiency of dye removal is increased by increasing absorbent dosage, so that removal efficiency was increased to 98.41 and $96.97 \%$ respectively by increasing concentration from 1 to $10 \mathrm{~g} / \mathrm{l}$. In the study on Direct Black 22 dye removal from aqueous solution by activated carbon made from orange peel, it is reported that by increasing the adsorbent dosage from 0.1 to $1 \mathrm{~g} / 1$, respectively, removal efficiency increased as 87.1 and 95.2\% (39). In the study on removal of acid orange 2 using egg shells from aqueous solutions, it is reported that with increasing adsorbent dosage, dye removal efficiency increased so that by increasing the adsorbent dose from 10 to $50 \mathrm{~g} / 1$, dye removal efficiency has been achieved as $35-74 \%$. It happens because of increase in the available or active surface area (40). The highest efficiency was obtained in high concentrations in the current work which corresponded with the results of the above studies. Thus, the initial concentration as $10 \mathrm{~g} / \mathrm{l}$ is introduced as the optimum concentration. 


\subsection{Effect of Dye Concentration}

In the adsorption process, the initial concentration of ions of the adsorbed material in the solution has a key role as the driving force to overcome the resistance of mass transfer between the fluid phase and solid phase (38). Figure 6 shows the initial concentration of dye for absorption by tea residue in the range of 50-500 $\mathrm{mg} / \mathrm{L}$. Figure 6 shows that by lowering dye concentration, absorption efficiency is increased. In a study on removal of Reactive Orange 3 from aqueous solutions using bio-sorption technology, it has been reported that dye removal efficiency was reduced by increasing dye concentration in the fixed condition. The reason is justified as follows: the lower the concentration of contaminant in contact with a specific amount of absorbent is, there is higher probability for absorption on the absorbent (36). In the study on pomegranate seed powder used in removal of Reactive Red 198 dye from aqueous solutions it is reported that with increasing initial concentration of dye from 25 to $50 \mathrm{mg} / \mathrm{L}$, dye removal efficiency decreased. It is due to reduction of the absorbent resistance against the absorption of the pollutants considered (41). In addition, adsorbed molecules in the solution compete with each other at higher concentrations to achieve the absorption positions, and absorption level reduces at higher doses. The highest efficiency was achieved at low concentrations in the current work that corresponded with the above studies. Thus, the initial concentration of 50 $\mathrm{mg} / \mathrm{l}$ with $41.98 \%$ efficiency is introduced as the optimal concentration.

\subsection{Impact of Contact Time on Absorption Rate}

Contact time is one of the main factors affecting absorption processes (42). Figure 7 indicates impact of optimal contact time for Acid Orange absorption in $\mathrm{pH} 2$ and concentration of $50 \mathrm{mg} / \mathrm{L}$. Figure 7 shows that dye removal efficiency was increased by increasing contact time. Ghaneian et al. (2012), in their study on application of pomegranate seed powder for removal of Reactive Red 198 dye from aqueous solution it was reported that with increasing contact time, removal efficiency increased. However, the maximum adsorption was reached in 30 minutes and adsorption equilibrium was reached in about 2 hours. It is due to quick absorption of dye molecules on the external surface of the absorbent at the beginning of the absorption process. Speed of the pollutant emissions inside the pores and thus the rate of absorption is reduced gradually due to relative electrostatic repulsion forces of surface negative charges absorbed on the absorbent surface and negative charges in the fluid mass (41). In this study on removal of acid orange 2 dye using egg shells from aqueous solutions, it has been reported that with increasing the duration time from 15 to 90 minutes, dye removal efficiency increased from 61 to $74 \%$. It happens because of the emptiness of many absorbent sites at the time of initial contact and change in the pollutant concentration in the liquid phase (40). In addition, contact between pollutants and absorbent is more likely by increasing the contact time and absorption of the pollutant by absorbent increases. In this study, efficiency was obtained as $41.98 \%$ at 120 minutes, which corresponds with the results of the above studies. Therefore, in this study, the retention time of 2 hours will be introduced as the optimal exposure time.

\subsection{Impact of Temperature on Absorption Rate}

Figure 8 indicates impact of optimal temperature on absorption efficiency. Figure 8 shows that absorption is increased by increasing temperature. In a study on basic red 46 dye removal from contaminated water using hardened Portland cement pieces as absorbent, it was reported that absorption was increased by increasing temperature. It is due to endothermic and the chemical absorption nature of the process (43). In a study on the application of egg shell as a natural absorbent for removal of Reactive Red 123 dye from synthetic textile wastewater, it was reported that in the temperature range of $-45^{\circ} \mathrm{C}$, removal efficiency increased with a temperature increase and then decreased. It is assigned to the change in the contaminant structure or surface characteristics of the absorbent used at higher temperatures resulting in decreased absorption efficiency (41). In addition, number of contacts between particles and absorbent surface is increased ad absorption is increased by increasing temperature. Highest removal efficiency was obtained at $50{ }^{\circ} \mathrm{C}$ in this study which is consistent with the above studies.

\subsection{Absorption Isotherms}

Adsorption isotherms indicate absorbent molecules in equilibrium between liquid and solid phases. Basis of isotherms is in the description of the behavior of the absorbed participle and the absorbent as well as providing an important plan of absorption type (44). Freundlich and Langmuir adsorption isotherm models are investigated in Figures 9 and 10. Figures 8 and 9 show that dye adsorption is more following the Freundlich isotherm. In the study of absorption of Acid Red 18 dye using bio-adsorbent Sargassum Glaucescens from aqueous solution, it was reported that the absorption process follows Freundlich isotherm $\left(\mathrm{R}^{2}=0.992\right)$ which represents the multi-layer nature of dye removal process (45). In the study on methylene blue dye removal from synthetic wastewater using bone ash it was reported that the dye absorption on bone ash follows the Freundlich isotherm due to higher correlation 
coefficient $\left(\mathrm{R}^{2}=0.99\right)(46)$. In this study, the adsorption of acid orange 7 dye on tea residue followed the Freundlich isotherm with a regression coefficient of 0.993 , and corresponded with the results of the above studies.

\section{Conclusions}

This study aimed to evaluate the efficiency of Acid Orange 7 dye by surface adsorption process using tea residue. Study results showed that the optimum conditions for a reduction of $50 \mathrm{mg} / 1$ of the dye with an efficiency of $98.41 \%$ is obtained under $\mathrm{pH} 2,10 \mathrm{~g} / \mathrm{l}$ as adsorbent dose and contact time of 120 minutes, at a temperature of $30{ }^{\circ} \mathrm{C}$. Thus, the results show that adsorption of Acid Orange 7 dye by the respective absorbent is influenced by various parameters such as $\mathrm{pH}$, absorbent dose, initial dye concentration, contact time and temperature such that dye removal efficiency has direct relationship with increasing the adsorbent dose, contact time and temperature, and it is inversely related with increasing $\mathrm{pH}$ and initial dye concentration. Equilibrium data in this study was obtained to follow Freundlich isotherm. According to the granular structure of CTC tea residue (fine-grained tea), raw absorbent is an appropriate and cheap adsorbent in surface adsorption of Acid Orange 7 dye from an aquatic environment.

\section{Acknowledgments:}

The authors gratefully acknowledge the Research Council of Gonabad University of Medical Sciences for financial support with GN 95/4 and also the respectable personnel of the Gonabad Environmental Protection Organization.

\section{Conflict of Interest:}

There is no conflict of interest to be declared.

\section{Authors' contributions:}

All authors contributed to this project and article equally. All authors read and approved the final manuscript.

\section{References:}

1) Zhou T, Lu X, Wang J, Wong FS, Li Y. Rapid decolorization and mineralization of simulated textile wastewater in a heterogeneous Fenton like system with/without external energy. J Hazard Mater. 2009; 165(1-3): 193-9. doi: 10.1016/j.jhazmat.2008.09.100. PMID: 18992989.

2) Yarmohammadi H, Ziaei M, Poursadeghiyan M, Moradi M, Fathi B, Biglari H, et al. Evaluation of Occupational Risk Assessment of Manual Load Carrying Using KIM Method on Auto Mechanics in Kermanshah City in 2015. Research Journal of Medical Sciences. 2016; 10(3): 116-9. doi: 10.3923/rjmsci.2016.116.119.

3) Rahmanpour Salmani E, Ghorbanian A, Ahmadzadeh S, Dolatabadi M, Nemanifar N. Removal of Reactive Red 141 Dye from Synthetic Wastewater by Electrocoagulation Process: Investigation of Operational Parameters. Iranian Journal of Health, Safety and Environment. 2016; 3(1): 403-11.

4) dos Santos AB, Cervantes FJ, van Lier JB. Review paper on current technologies for decolourisation of textile wastewaters: perspectives for anaerobic biotechnology. Bioresour Technol. 2007; 98(12): 2369-85. doi: 10.1016/j.biortech.2006.11.013. PMID: 17204423 .

5) Biglari H, Afsharnia M, Alipour V, Khosravi R, Sharafi K, Mahvi AH. A review and investigation of the effect of nanophotocatalytic ozonation process for phenolic compound removal from real effluent of pulp and paper industry. Environ Sci Pollut Res Int. 2017; 24(4): 4105-16. doi: 10.1007/s11356-016-8079-x. PMID: 27933497.

6) Biglari H, Chavoshani A, Javan N, Mahvi AH. Geochemical study of groundwater conditions with special emphasis on fluoride concentration, Iran. Desalination and Water Treatment. 2016; 57(47): 1-8. doi: 10.1080/19443994.2015.1133324.

7) Biglari H, Afsharnia M, Javan N, Sajadi A. Phenol Removal from Aqueous environment by Adsorption onto Activated Carbon of Meswak's Root treated with KMnO4. Iranian Journal of Health Sciences. 2016; 4(1): 20-30. doi: 10.18869/acadpub.jhs.4.1.20.

8) Konsowa A, El-Rahman HA, Moustafa M. Removal of azo dye acid orange 7 using aerobic membrane bioreactor. Alexandria Engineering Journal. 2011; 50(1): 117-25. doi: 10.1016/j.aej.2011.01.014.

9) Khandan M, Eyni Z, Ataei manesh L, Khosravi Z, Biglari H, Koohpaei A, et al. Relationship Between Musculoskeletal Disorders and Job Performance among Nurses and Nursing Aides in Main Educational Hospital in Qom Province, 2014. Research Journal of Medical Sciences. 2016; 10(4): 307-12. doi: 10.3923/rjmsci.2016.307.312.

10) Tanyildizi MŞ. Modeling of adsorption isotherms and kinetics of reactive dye from aqueous solution by peanut hull. Chemical Engineering Journal. 2011; 168(3): 1234-40. doi: 10.1016/j.cej.2011.02.021. 
11) Noroozi B, Sorial GA. Applicable models for multi-component adsorption of dyes: A review. J Environ Sci (China). 2013; 25(3): 419-29. doi: 10.1016/S1001-0742(12)60194-6. PMID: 23923413.

12) Zhang L, Cheng Z, Guo X, Jiang $X$, Liu R. Process optimization, kinetics and equilibrium of orange G and acid orange 7 adsorptions onto chitosan/surfactant. Journal of Molecular Liquids. 2014; 197: 353-67. doi: 10.1016/j.molliq.2014.06.007.

13) Bazrafshan E, Biglari H, Mahvi AH. Humic acid removal from aqueous environments by electrocoagulation process using iron electrodes. Journal of Chemistry. 2012; 9(4): 2453-61. doi: $10.1155 / 2012 / 876739$.

14) Mirzabeygi M, Naji M, Yousefi N, Shams M, Biglari H, Mahvi AH. Evaluation of corrosion and scaling tendency indices in water distribution system: a case study of Torbat Heydariye, Iran. Desalination and Water Treatment. 2016; 57(54): 25918-26. doi: 10.1080/19443994.2016.1162206.

15) Yarmohammadi H, Poursadeghiyan M, Shorabi Y, Ebrahimi MH, Rezaei G, Biglari H, et al. Risk Assessment in a Wheat Winnowing Factory Based on ET and BA Method. 2016; 11(3): 334-8. doi: 10.3923/jeasci.2016.334.338.

16) Jin X, Yu B, Chen Z, Arocena JM, Thring RW. Adsorption of Orange II dye in aqueous solution onto surfactant-coated zeolite: Characterization, kinetic and thermodynamic studies. J Colloid Interface Sci. 2014; 435: 15-20. doi: 10.1016/j.jcis.2014.08.011. PMID: 25217725.

17) Xin Q, Fu J, Chen Z, Liu S, Yan Y, Zhang J, et al. Polypyrrole nanofibers as a high-efficient adsorbent for the removal of methyl orange from aqueous solution. Journal of Environmental Chemical Engineering. 2015; 3(3): 1637-47. doi: 10.1016/j.jece.2015.06.012.

18) Bazrafshan E, Biglari H, Mahvi AH. Phenol removal by electrocoagulation process from aqueous solutions. Fresenius Environmental Bulletin. 2012; 21(2): 364-71.

19) Biglari H, Sohrabi Y, Charganeh S, Dabirian M, Javan N. Surveying the Geographical Distribution of Aluminium Concentration in Groundwater Resources of Sistan and Baluchistan, Iran. Research Journal of Medical Sciences. 2016; 10(4): 351-4. doi: 10.3923/rjmsci.2016.351.354.

20) Crini G, Badot PM. Application of chitosan, a natural aminopolysaccharide, for dye removal from aqueous solutions by adsorption processes using batch studies: A review of recent literature. Progress in polymer science. 2008; 33(4): 399-447. doi: 10.1016/j.progpolymsci.2007.11.001.

21) Sharafi K, Mansouri Y, Zinatizadeh AA, Pirsaheb M. Adsorptive removal of Methylene Blue from aqueous solutions by pumice powder: Process modelling and kinetic evaluation. Environmental Engineering \& Management Journal. 2015; 14(5).

22) Yagub MT, Sen TK, Afroze S, Ang HM. Dye and its removal from aqueous solution by adsorption: a review. Adv Colloid Interface Sci. 2014; 209: 172-84. doi: 10.1016/j.cis.2014.04.002. PMID: 24780401.

23) Alipour V, Nasseri S, Nabizadeh Nodehi R, Mahvi AH, Rashidi A. Preparation and application of oyster shell supported zero valent nano scale iron for removal of natural organic matter from aqueous solutions. J Environ Health Sci Eng. 2014; 12(1): 146. doi: 10.1186/s40201-014-0146-y. PMID: 25648623, PMCID: PMC4300684.

24) Kim Y, Bae J, Park H, Suh JK, You YW, Choi H. Adsorption dynamics of methyl violet onto granulated mesoporous carbon: Facile synthesis and adsorption kinetics. Water Res. 2016; 101: 187-94. doi: 10.1016/j.watres.2016.04.077. PMID: 27262123.

25) Khosravi R, Shahryari T, Halvani A, Khodadadi M, Ahrari F, Mehrizi EA. Kinetic analysis of organic matter removal in stabilization pond in the wastewater treatment plant of Birjand. Advances in Environmental Biology. 2013; 7(6): 1182-8.

26) Verma AK, Dash RR, Bhunia P. A review on chemical coagulation/flocculation technologies for removal of colour from textile wastewaters. Journal of Environmental Management. 2012; 93(1): 154-68. doi: 10.1016/j.jenvman.2011.09.012. PMID: 2205458.

27) Auta M, Hameed B. Preparation of waste tea activated carbon using potassium acetate as an activating agent for adsorption of Acid Blue 25 dye. Chemical Engineering Journal. 2011; 171(2): 502-9. doi: 10.1016/j.cej.2011.04.017.

28) Dibah H, Majd A, Nejadsattari T, Ghanati F. Allelopathic potential of Camellia sinensis L. (kuntze) on seed germinationand seedling growth of Vicia sp. Advances in Environmental Biology. 2012; 6(11): 2846-53.

29) Borah L, Goswami M, Phukan P. Adsorption of methylene blue and eosin yellow using porous carbon prepared from tea waste: adsorption equilibrium, kinetics and thermodynamics study. Journal of Environmental Chemical Engineering. 2015; 3(2): 1018-28. doi: 10.1016/j.jece.2015.02.013. 
30) Foroughi dahr M, Abolghasemi H, Esmaieli M, Nazari G, Rasem B. Experimental study on the adsorptive behavior of Congo red in cationic surfactant-modified tea waste. Process Safety and Environmental Protection. 2015; 95: 226-36. doi: 10.1016/j.psep.2015.03.005.

31) Mansouri N, Pourmahabadian M, Ghasemkhani M. Road traffic noise in downtown area of Tehran. Journal of Environmental Health Science \& Engineering. 2006; 3(4): 267-72.

32) Anastopoulos I, Kyzas GZ. Agricultural peels for dye adsorption: a review of recent literature. Journal of Molecular Liquids. 2014; 200: 381-9. doi: 10.1016/j.molliq.2014.11.006.

33) Ogata F, Imai D, Kawasaki N. Cationic dye removal from aqueous solution by waste biomass produced from calcination treatment of rice bran. Journal of Environmental Chemical Engineering. 2015; 3(3): 147685. doi: 10.1016/j.jece.2015.05.025.

34) Mahmoud DK, Salleh MAM, Karim WAWA, Idris A, Abidin ZZ. Batch adsorption of basic dye using acid treated kenaf fibre char: equilibrium, kinetic and thermodynamic studies. Chemical Engineering Journal. 2012; 181: 449-57. doi: 10.1016/j.cej.2011.11.116.

35) Zazouli MA, Balarak D, Mahdavi Y, Ebrahimi M. Adsorption rate of 198 reactive red dye from aqueous solutions by using activated red mud. Iranian journal of health sciences. 2013; 1(1): 36-43. doi: 10.18869/acadpub.jhs.1.1.36.

36) Saghi M, Allahabadi A, Rahmani SA, Vazeiri T, Hekmatshoar R. Removal of reactive orange 3 dye from aqueous solution by biosorption technology. Journal of Sabzevar University of Medical Sciences. 2012; 19(2(64)): 127-35.

37) Bazrafshan E, Rahdar S, Balarak D, Kord Mostafapour F, Zazouli MA. Equilibrium and Thermodynamics Studies for Decolorization of Reactive Black 5 by Adsorption onto Acid Modified Banana Leaf Ash. Iranian Journal of Health Sciences. 2015; 3(3): 15-28.

38) Yousefi N, Fatehizadeh A, Ahmadi A, Rajabizadeh A, Toolabi A, Ahmadian M. The efficiency of modified wheat brad in reactive black 5 dye removal from aqueous solutions. Journal of Health and Development. 2013; 2(2): 157-69.

39) Gholami H, Gholami M, Gholizadeh A, Rastegar A. Use of orange Peel ash for removal of direct black 22 dye from aqueous Environments. Journal of North Khorasan University of Medical Sciencs. 2012; 4(1(11)): 45-56.

40) Yari AR, Majidi G, Tanhaye Reshvanloo M, Ansari M, Nazari S, Emami Kale Sar M, et al. Using Eggshell in Acid Orange 2 Dye Removal from Aqueous Solution. Iranian Journal of Health Sciences. 2015; 3(2): 3845.

41) Ghaneian MT, Dehvari M, Taghavi M, Amrollahi M, Jamshidi B. Application of Pomegranate Seed Powder in the removal of Reactive Red 198 dye from aqueous solutions. Jundishapur Journal of Health Sciences. 2012; 4(3): 45-55.

42) Sobhanardakani S, Zandipak R. Removal of Anionic Dyes (Direct Blue 106 and Acid Green 25) from Aqueous Solutions Using Oxidized Multi-Walled Carbon Nanotubes. Iranian Journal of Health Sciences. 2015; 3(3): 48-57. doi: 10.7508/ijhs.2015.03.006.

43) Saadatjou N, Rasoulifard M, Heidari A. Removal of Basic Red 46 using low-cost adsorbent of hardened paste of portland cement from contaminated water. J Color Sci Tech. 2009; 2(4): 221-6.

44) Jafari Mansoorian H, Mahvi A, Kord Mostafapoor F, Alizadeh M. Equilibrium and synthetic studies of methylene blue dye removal using ash of walnut shell. Journal of Health in the Field. 2013; 1(3): 48-55.

45) Zazouli MA, Moradi E. Adsorption Acid Red18 dye using Sargassum Glaucescens biomass from aqueous solutions. Iranian Journal of Health Sciences. 2015; 3(2): 7-13. doi: 10.7508/ijhs.2015.02.002.

46) Ghanizadeh G, Asgari G. Removal of methylene blue dye from synthetic wastewater with bone char. Iranian Journal of Health and Environment. 2009; 2(2): 104-13. 